\title{
SUSPENSIÓN DE GARANTÍAS. ANÁLISIS DEL ARTÍCULO 29 CONSTITUCIONAL
}

\author{
Gustavo de Silva GuTIÉRREZ*
}

RESUMEN: El presente estudio es una posible interpretación del artículo 29 constitucional, con la finalidad alterna de proponer soluciones a potenciales problemas jurídicos que puedan surgir de su futura aplicación, derivados de omisiones textuales en el precepto y la escasa interpretación del mismo por los órganos de interpretación constitucional. En el mismo se analizan la naturaleza jurídica de las garantías individuales para concluir la finalidad del procedimiento previsto en el artículo en estudio, el orden jurídico en que se desenvuelve, las autoridades que intervienen, las causas generadoras y los efectos del mismo, el contenido y forma que deben tener los actos emitidos en éste y los límites que el propio artículo impone a la actuación del Estado en este tema. El trabajo concluye con algunas consideraciones respecto a la repercusión que sobre dicha materia tienen algunos instrumentos internacionales, así como del control jurisdiccional en sede constitucional de los actos emitidos en aplicación del citado artículo 29 de la Constitución.

Palabras clave: suspensión de garantías individuales, interpretación constitucional, derechos humanos, control constitucional.
ABSTRACT: The present study is a possible interpretation of the constitutional article 29 , with the alternated finality to offer solutions to potentials juridical problems that can arise from its future application, derived from textual omissions in the precept and the insufficient interpretation of the same from the organs of constitutional interpretation. In this study are analyzed the juridical nature of the constitutional rights to conclude the finality of the proceeding provided in the article in study, the juridical order in which it is developed, the authorities that take part, the generating causes and the effects of this proceeding, the content and from that should have the emitted acts in this one and the limits that the article impose on to the State in this subject. The work conclude with some considerations respect to the repercussion that about this subject have some international instruments, as soon as to the constitutional control of the emitted acts from the authorities when the article 29 of the Constitution is applied.

Descriptors: Suspension of Individual guarantees, Constitutional interpretation, Human Rights, judicial review.

* Abogado especialista en derecho constitucional y catedrático del ITAM.

Fecha de recepción: 1o. de diciembre de 2007.

Fecha de dictamen: 2 de julio de 2008. 


\section{GARANTÍAS INDIVIDUALES}

"Toda comunidad en la que no esté estipulada la separación de poderes y la seguridad de derechos necesita una Constitución".

Esta disposición contenida en el artículo 16 de la Déclaration des Droits de l'Homme et du Citoyen, otorgada en la Francia de 1789, constituye una premisa indispensable sin la cual estaríamos impedidos para hablar de Estado de derecho.

Junto con otras características (división de poderes, imperio de la ley, y legalidad de la administración), el establecimiento de garantías individuales (o derechos fundamentales) ${ }^{1}$ constituye un elemento indispensable para el Estado constitucional o de derecho. ${ }^{2}$ Así lo han advertido nuestros constituyentes desde 1824 hasta nuestros días.

En efecto, nuestro sistema constitucional otorga diversos derechos ${ }^{3}$ fundamentales que forman parte toral del ordenamiento jurídico, y dada su importancia, son normados al máximo nivel de la estructura jurídica del Estado, es decir, en la propia Constitución.

El primer párrafo del artículo 1o. de la Constitución Política de los Estados Unidos Mexicanos ${ }^{4}$ determina que las garantías individuales no pueden ser restringidas ni suspendidas; salvo en aquellos casos en que la propia norma fundamental lo permite.

El primer problema que plantea dicha disposición es el relativo al grado de modificación que pueden sufrir las normas constitucionales que contienen las garantías individuales. Parece claro que pueden ser objeto de adición o reforma la ampliación de su ámbito de protección respecto del gobernado; pero ha sido más discutida la posibilidad de reforma que limite el alcance de dichos preceptos o, más aún, la derogación de los mismos.

1 Para efectos del presente trabajo utilizaremos los términos de garantías individuales y derechos fundamentales como sinónimos, pues para el autor refieren al mismo tipo de normas jurídicas.

2 Cfr. Díaz, Elías, Estado de derecho y sociedad democrática, 9a. ed., Madrid, Taurus, 1981, p. 31.

3 O como veremos más adelante, impone límites a los órganos del Estado.

4 Artículo 1o. En los Estados Unidos Mexicanos todo individuo gozará de las garantías que otorga esta Constitución, las cuales no podrán restringirse ni suspenderse, sino en los casos y con las condiciones que ella misma establece. 
Algunos autores ${ }^{5}$ consideran que dada la disposición indicada, las garantías individuales no pueden derogarse. Coincidimos en el sentido de que la totalidad de los derechos fundamentales no pueden derogarse sustituyéndolos por un vacío normativo sin desquebrajar nuestro Estado de derecho. ${ }^{6}$ En contrario, no coincidimos por lo que respecta a la derogación de alguna o algunas garantías individuales en particular.

En efecto, de conformidad con el artículo 135 constitucional, el "Constituyente Permanente" se encuentra facultado para reformar o adicionar los preceptos constitucionales, sin existir disposición expresa que excluya de entre dichos preceptos a las garantías individuales. ${ }^{7}$ Por otra parte, si bien es cierto que la disposición contenida en el artículo citado no incluye expresamente la posibilidad de derogación, también lo es que nuestra práctica constitucional así lo ha admitido respecto de otras normas constitucionales. Finalmente, por lo que respecta a la disposición del artículo 1o., ésta permite la modificación de las garantías individuales en los términos establecidos en la Constitución, incluido desde luego, en nuestro criterio, el procedimiento de reforma previsto en el artículo 135 constitucional.

Además del discutible tema de modificación de garantías individuales mediante el procedimiento establecido en el artículo 135 del pacto federal, la Constitución establece en su artículo 29 un procedimiento tendiente a la suspensión de las mismas. Es también a este procedimiento al que refiere el artículo 1o. constitucional.

Como hemos indicado, las garantías individuales a que se refieren los artículos 1o. y 29 constitucionales son, en primer término, normas constitucionales en virtud de su pertenencia a la norma suprema. Sin embargo, se diferencian de otras normas del mismo rango en virtud de ser consideradas como: a) derechos públicos subjetivos, ${ }^{8}$ en la medida en que son otorgados a la persona en su calidad de gobernado y oponibles al Estado; o, b) disposiciones que determinan los contenidos necesarios, ex-

5 Cfr. Burgoa, Ignacio, Las garantías individuales, 25a. ed., México, Porrúa, 1993, pp. 262-265.

6 Lo anterior, puesto que sin derechos fundamentales no es posible hablar de Estado de derecho.

7 Donde la ley no distingue, no hay que distinguir.

8 Ibidem, p. 187. 
cluidos o potestativos de las normas jurídicas secundarias. ${ }^{9}$ En este segundo caso, más que derechos del gobernado serán normas que contienen obligaciones dirigidas a los órganos del Estado.

Desde luego que ambas definiciones pueden encontrar relación en la medida en que para algunos autores la Constitución es una norma que limita al poder y garantiza los derechos de los gobernados, ${ }^{10}$ encontrando una íntima relación entre los derechos emanados de éstas y el modo de organizar y ejercer las funciones estatales por los órganos de gobierno. ${ }^{11}$

No obstante, aunque pueda parecer que ambas concepciones respecto de las garantías individuales (como derechos del gobernado o como obligaciones y límites a respetar por los órganos del Estado) se encuentran en una relación bilateral, observamos que no es así, ${ }^{12}$ inclinándonos por considerar más apropiado identificar a las garantías individuales como normas que establecen los límites del poder.

Los criterios indicados adquieren relevancia teórica para el presente trabajo, además, en virtud de que conforme al primero, el artículo 29 constitucional suspende derechos de los gobernados, despojándolos (aunque temporalmente) de lo ya otorgado; desde la segunda perspectiva, la suspensión de garantías es el levantamiento de las limitantes establecidas a los órganos de gobierno, permitiéndole con esto a los mismos una actuación más efectiva.

9 Cfr. Schmill, Ulises, El sistema de la Constitución mexicana, México, Porrúa, 1971, p. 363.

10 Cfr. Rubio Llorente, Francisco, La forma del poder, Madrid, Centro de Estudios Constitucionales, 1997, p. 207.

11 Cfr. Pérez Luño, Antonio E., Los derechos fundamentales, 5a. ed., Madrid, Tecnos, 1993, p. 20.

12 Por no ser el objetivo del presente trabajo, nos limitaremos a indicar que una norma jurídica no necesariamente contiene una relación bilateral mediante la que, el establecimiento de un derecho implica la recíproca obligación y viceversa, puesto que existirá el derecho o la obligación sólo en la medida en que así sea previsto en la norma jurídica, pudiendo obtener una idea del opuesto correlativo como reflejo de la norma, pero sin que este exista realmente en el ordenamiento jurídico. Es decir, el establecimiento de un derecho por la norma, puede generarme la idea de una obligación correlativa de un tercero y viceversa (la obligación de un tercero puede generarme la idea de un derecho), pero no en todos los casos, esa percepción o consecuencia se encontrará plasmada positivamente. 


\section{JUSTIFICACIÓN Y NATURALEZA JURÍDICA DE LA SUSPENSIÓN DE GARANTÍAS}

En el ordenamiento constitucional se encuentra el establecimiento del Estado como el principal sistema de organización social. Al organizar al Estado, el derecho otorga al gobierno (como elemento del Estado) la rectoría básica de conducta social mediante la obligatoria observancia y aplicación de las normas jurídicas; sin embargo, como hemos indicado, la función gubernativa no es ilimitada, sino que se encuentra restringida y orientada por los derechos fundamentales consagrados en la norma creadora del Estado y constituyente del gobierno.

\section{Justificación}

Las garantías individuales son normas constitucionales a respetar por los órganos estatales, que deben operaran en todo momento en una normalidad social.

No obstante, esa normalidad de orden social que sustenta el derecho puede verse en extremo amenazada por diversas circunstancias, ante lo cual, es necesaria la intervención del gobierno en forma rápida y eficaz a fin de garantizar, precisamente, la continuidad del orden prestablecido y más aún, probablemente, la supervivencia del propio Estado.

Para favorecer la eficacia en la acción de gobierno será necesario suspender las disposiciones normativas que puedan obstaculizar la citada actuación y, específicamente, las que contienen los derechos fundamentales. En estos casos, el derecho admite que nos encontramos ante un interés superior a cualquier derecho particular, ante el interés del Estado.

Coincidimos pues en que

la suspensión de las garantías individuales se justifica por la necesidad política de que los órganos gubernativos tengan libertad de acción para proceder con rapidez y energía a mantener el orden público mediante la eliminación radical de las situaciones y circunstancias de hecho que agreden los intereses sociales... ${ }^{13}$

El artículo 29 de la Constitución Política de los Estados Unidos Mexicanos establece:

13 Bazdresch, Luis, Garantías constitucionales, 5a. ed., México, Trillas, 1998, p. 38. 
En los casos de invasión, perturbación grave de la paz pública, o de cualquier otro que ponga a la sociedad en grave peligro, solamente el presidente de los Estados Unidos Mexicanos, de acuerdo con los titulares de las secretarías de estado, los departamentos administrativos y la Procuraduría General de la República y con aprobación del Congreso de la Unión, y en los recesos de éste, de la Comisión Permanente, podrá suspender en todo el país o en lugar determinado las garantías que fuesen obstáculo para hacer frente, rápida y fácilmente a la situación; pero deberá hacerlo por tiempo limitado, por medio de prevenciones generales y sin que la suspensión se contraiga a determinado individuo. Si la suspensión tuviese lugar hallándose el Congreso reunido, éste concederá las autorizaciones que estime necesarias para que el Ejecutivo haga frente a la situación, pero si se verificase en tiempo de receso, se convocará sin demora al Congreso para que las acuerde.

Como podemos observar, el propio Constituyente justificó la suspensión de garantías ante determinadas situaciones.

El establecimiento de derechos fundamentales es, como indicamos con anterioridad, elemento indispensable en que diversos autores coinciden al hablar de Estado de derecho, mas pueden existir determinadas circunstancias en las que ante la supervivencia del mismo Estado no se pueden anteponer requisitos o limitantes de tipo alguno que obstaculicen la acción del propio Estado para garantizar su continuidad; esto se encuentra íntimamente relacionado con lo que en teoría del Estado o ciencia política se ha denominado razón de Estado. ${ }^{14}$ Actualmente se puede identifi-

14 Estrictamente hablando, la razón de Estado es un término acuñado por Nicolás Maquiavelo para referirse a las medidas racionales que un gobernante debe tomar con objeto de conservar la salud y la fuerza de un Estado. La razón de Estado está estrechamente vinculada con el problema de la legitimidad del Estado que surge con los Estados-Nación modernos. No obstante, con gran frecuencia la razón de Estado se ha utilizado para justificar medidas de dudosa ética o abiertamente tiránicas, por lo que la expresión ha cobrado muy mala fama y conlleva una significación negativa. Hasta el extremo de que en la actualidad "por razón de Estado" se utiliza de manera generalizada para definir las medidas ilegales o ilegítimas tomadas por un gobierno con intención de mantener el orden establecido o mejorar su posición frente a enemigos y disidentes. Fue quizás el cardenal Richelieu quien primero utilizó de manera extensiva la razón de Estado para garantizar la supervivencia de un determinado orden, atendiendo únicamente a la razón y sin considerar la naturaleza ética de los medios utilizados: la razón de Estado estima lícito un mal menor si con ello se evita un mal mayor. La filosofía política y la ciencia jurídica contemporánea prestan gran atención a este concepto y sus derivaciones. En general, suele entenderse que la razón de Estado no debería exceder los límites de la legi- 
car a la razón de Estado como la ruptura del orden jurídico (o mejor dicho, del Estado de derecho) por el poder político, para lograr la supervivencia del Estado ante determinadas circunstancias que lo amenazan.

Ahora bien, consideramos que a fin evitar una práctica como la razón de Estado que en el mundo jurídico-positivo es criticable, el Constituyente la convirtió en derecho positivo, estableciendo los lineamientos necesarios para su activación, lo cual, desde luego, no elimina por completo la posibilidad de dicha práctica de razón de Estado, pero al menos, genera la dificultad para acudir a ella sin antes agotar los medios que el propio Estado de derecho propone. Es decir, si bien es cierto que la razón de Estado y el procedimiento previsto en el artículo 29 constitucional no deben confundirse, también lo es que permiten vislumbrar una relación de conexidad, mediante la cual, en algunos casos, el Estado de derecho, a través del derecho positivo, impide la justificación doctrinaria de la razón de Estado (que es contraria al derecho).

Así, "en los sistemas jurídicos de derecho escrito, la ley fundamental resuelve la regulación normativa de este fenómeno, y si no se respeta o no contempla su reglamentación, la aplicación de las medidas señaladas se traducen en el quebrantamiento de la Constitución". ${ }^{15}$ El régimen que se genera con la aplicación del artículo 29 constitucional es conocido también como régimen de excepción o estado de sitio. ${ }^{16}$

Necesaria es pues la actuación rápida y eficaz del gobierno ante la amenaza hacia el Estado, debiendo romper temporalmente el derecho que la sociedad reconoce en la normalidad, mediante la estricta aplicación y respeto del mismo. "Ábrase así la puerta, que en épocas normales no puede franquear la autoridad sin cometer violación". ${ }^{17}$

Dicha medida, aunque prevista por el ordenamiento jurídico, lo esfuerza a un límite que, no obstante permisible, puede llamar a apetitos

timidad del Estado. Véase Colaboradores de Wikipedia. Razón de Estado [en línea]. Wikipedia, la enciclopedia libre, 2007 [fecha de consulta: 12 de octubre de 2007]. Disponible en http://es.wikipedia.org/w/index.php?title $=$ Raz $\% C 3 \% B 3 n \_$de_Estado\&oldid=9714024.

15 Sánchez Bringas, Enrique, Derecho constitucional, 4a. ed., México, Porrúa, 1999, pp. 248 y 249 .

16 Cfr. Madrazo, Jorge, “Artículo 29”, Constitución Política de los Estados Unidos Mexicanos comentada, 4a. ed., México, UNAM, Instituto de Investigaciones Jurídicas y otras, 1993, p. 136.

17 Tena Ramírez, Felipe, Derecho constitucional mexicano, 29a. ed., México, Porrúa, 1995, p. 220. 
dictatoriales o generadores de cambios jurídicos que den muerte al sistema establecido, hasta entonces válido y regente.

\section{Naturaleza jurídica}

En el sistema jurídico mexicano coexisten tres diversos órdenes normativos, a saber: a) el orden constitucional; b) el orden federal, y c) el orden local. Las normas locales se excluyen entre sí espacialmente, mientras que entre éstas y las federales se genera una exclusión competencial (o material). Así, entre los órdenes federal y locales no existe una cuestión jerárquica sino competencial.

El orden constitucional es creado en la Constitución y para la Constitución. Dicho orden es jerárquicamente superior a los órdenes federal y locales. Por otra parte, las autoridades que desarrollan las funciones emanadas del orden constitucional, son las mismas que desarrollan las competencias del orden federal o locales, son órganos específicos formados por combinaciones sui generis de órganos federales y locales.

Dentro del orden constitucional encontramos por lo menos las siguientes funciones: a) la reforma constitucional; b) la formación de nuevos estados de la Federación; c) los procesos constitucionales (amparo, controversias constitucionales y acciones de inconstitucionalidad), y d) el procedimiento de suspensión de garantías. ${ }^{18}$

Obsérvese que al igual que las funciones previstas en los incisos a), b) y c); la suspensión de garantías no puede considerarse una función del orden federal o del orden local. Es un procedimiento constitucional, establecido por la Constitución en relación con sus propias normas constitucionales (las que establecen derechos fundamentales). Aunque las autoridades que intervienen en el procedimiento pertenecen al orden federal, al momento en que participan en el procedimiento que nos ocupa, lo hace como autoridades del orden constitucional, pues la norma que aplican y justifica su actuación no es una norma federal, sino la Constitución. Finalmente, el resultado de su actuación será una norma jurídica jerárqui-

$18 C f r$. Schmill, Ulises y Silva, Gustavo de, "La sanción ante el incumplimiento de la sentencia de amparo", El Foro. La ejecución de sentencias de amparo, la repetición del acto reclamado y la negativa a suspenderlo, México, décimo cuarta época, t. XVIII, núm. 2, Barra Mexicana Colegio de Abogados, 2005, pp. 17 y 18. 
camente superior a las federales o locales; de igual forma, someterá a dichos órdenes jurídicos inferiores.

\section{ANTECEDENTES}

El procedimiento para alterar la observancia regular del orden jurídico ante situaciones de gravedad que pongan en peligro al propio Estado, es una posibilidad que se ha considerado en diversas organizaciones sociales, como la romana.

La suspensión de garantías individuales es, pues, un fenómeno que, con más o menos variantes ha sido acogido en nuestro derecho público, pudiendo decirse, en general que reconoce como antecedente remoto la institución de la dictadura en el derecho romano, en cuyo sistema correspondía al Senado la designación del dictador atendiendo a las situaciones de peligro que se presentaban en la vida del Estado, designación que debía ser aprobada por los cónsules. ${ }^{19}$

El dictador debería hacer la guerra; estaba por encima de la ley y decidía sobre la vida y la muerte. Su poder no se encontraba limitado por la magistratura u órgano diverso. Sin embargo, el nombramiento sí se encontraba temporalmente limitado y en caso de desaparecer las causas que originaron la institución de la "dictadura", el magistrado así nombrado dictador debía renunciar al cargo. ${ }^{20}$

Ahora bien, el procedimiento de suspensión de garantías, además de no ser propiamente una institución nacional, tampoco es de forma alguna, novedoso para nuestro sistema constitucional. Desde el proyecto de puntos constitucionales elaborado por Ignacio López Rayón en 1811, podemos encontrar un antecedente del mismo. ${ }^{21}$ En la Constitución de Cádiz de 1812, en su artículo 308 contenía un procedimiento similar alo actual en el que se establecía: "Si en circunstancias extraordinarias la

19 Burgoa, I., op. cit., nota 5, p. 210.

20 Cfr. Fix-Fierro, Héctor, Artículo 29. Derechos del Pueblo Mexicano, 4a. ed., México, Porrúa-LV Legislatura de la Cámara de Diputados del Congreso de la Unión, 1994, t. V, pp. 596 y 597.

21 El punto 14 indicaba: "Habrá un Consejo de Estado para los casos de declaración de guerra y ajuste de paz, a los que deberán concurrir los oficiales de brigadier arriba, no pudiendo la Suprema Junta determinar sin requisitos". 
seguridad del Estado exigiese, en toda la Monarquía o en parte de ella, la suspensión de alguna de las formalidades prescritas en este capítulo para el arresto de los delincuentes, podrán las Cortes decretarla por un tiempo determinado".22

Las Constituciones de 1824 y 1836 negaron la posibilidad de reconocimiento jurídico del estado de excepción, por lo que dichos ordenamientos carecían de dispositivo correlativo al analizado en el presente trabajo. Fue hasta las Bases Orgánicas de la República Mexicana de 1843, que en su artículo 198 estableció la posibilidad de suspender derechos fundamentales; derogándose dicha norma mediante el Acta Constitutiva y de Reformas de 1847. La Constitución de 1857 en su artículo 29 estableció precepto similar al vigente, prohibiendo en todo caso la suspensión de las garantías que aseguraran la vida del hombre. ${ }^{23}$

Procedimientos similares al de suspensión de garantías de nuestra Constitución de 1917, podemos encontrarlos en los ordenamientos jurídico-constitucionales de otros Estados.

En nuestra reciente historia constitucional, únicamente se han suspendido las garantías individuales con motivo de la participación de México en la segunda guerra mundial, apareciendo el decreto respectivo en el Diario Oficial de la Federación del 2 de junio de $1942 .{ }^{24}$

\section{EFECTOS DEL PROCEDIMIENTO \\ DEL ARTÍCULO 29 CONSTITUCIONAL}

Del procedimiento previsto en el artículo 29 constitucional transcrito con anterioridad, se pueden desprender dos efectos específicos: a) la suspensión de garantías propiamente dicha y, b) la autorización al Ejecutivo Federal para ejercer facultades extraordinarias.

22 La Constitución de Cádiz por haberse aplicado en territorio nacional (durante el virreinato en forma discontinua) y ser antecedente de nuestro ordenamiento jurídico. $C f r$. Ferrer Muñóz, Manuel, La Constitución de Cádiz y su aplicación en la Nueva España, México, UNAM, Instituto de Investigaciones Jurídicas, 1993, p. 18.

23 Cfr. Fix-Zamudio, Héctor y Carmona Tinoco, Jorge Ulises, "Algunos comentarios al título primero, capítulo primero de la Constitución federal", en Carbonell, Miguel y Valadés, Diego (coords.), Derechos fundamentales. Panorama del derecho constitucional mexicano, México, Porrúa, UNAM, 2006.

24 Este decreto no suspendió la totalidad de las garantías individuales previstas en la Constitución. 
Como indicamos en párrafos anteriores, la única forma válida de lograr la suspensión de preceptos constitucionales, en específico de las garantías individuales, es la prevista en el artículo 29 constitucional, mas dicho procedimiento no sólo obtiene la no aplicación temporal de preceptos constitucionales que contienen derechos fundamentales, sino que de igual forma genera la contravención jurídica de principios constitucionales que en situaciones normales son inquebrantables, como el de división de poderes, que de conformidad con el diverso artículo $49,{ }^{25}$ segundo párrafo del texto supremo, también tiene como excepción las facultades extraordinarias emanadas del propio artículo 29 y 131 segundo párrafo $^{26}$ constitucionales.

Así, en virtud de disposición constitucional expresa, el sistema jurídico permite la abstención de su observancia en aspectos torales del Estado de derecho: la división de poderes y las garantías individuales. ${ }^{27}$

Sin embargo, el que la propia norma constitucional permita su inobservancia parcial en relación con el debido cumplimiento acaecido en regularidad social, no implica que la acción de gobierno derivada del procedimiento que nos ocupa sea ilimitada o arbitraria. No se excepciona la observancia total del derecho; se permite su inaplicación parcial, pero con el apego estricto y continuo de las disposiciones no suspendidas, y principalmente de aquellas que le dan sustento al nuevo orden de cosas como el propio artículo 29 constitucional.

25 "Artículo 49. El Supremo Poder de la Federación se divide para su ejercicio en Legislativo, Ejecutivo y Judicial. No podrán reunirse dos o más de estos poderes en una sola persona o corporación, ni depositarse el Legislativo en un individuo, salvo el caso de facultades extraordinarias al Ejecutivo de la Unión, conforme a lo dispuesto en el artículo 29. En ningún otro caso, salvo lo dispuesto en el segundo párrafo del artículo 131, se otorgarán facultades extraordinarias para legislar".

26 “Artículo 131... El Ejecutivo podrá ser facultado por el Congreso de la Unión para aumentar, disminuir o suprimir las cuotas de las tarifas de exportación e importación, expedidas por el propio Congreso, y para crear otras; así como para restringir y para prohibir las importaciones, las exportaciones y el tránsito de productos, artículos y efectos, cuando lo estime urgente, a fin de regular el comercio exterior, la economía del país, la estabilidad de la producción nacional, o de realizar cualquiera otro propósito, en beneficio del país. El propio Ejecutivo al enviar al Congreso el Presupuesto de Fiscal de cada año, someterá a su aprobación el uso que hubiese hecho de la facultad concedida".

27 Justamente las exigidas en la Déclaration des Droits de l'Homme et du Citoyen, de 1789 e indicada al comienzo del presente trabajo. 


\section{De ese modo,}

las disposiciones involucradas en el artículo 29 constitucional implican no sólo la base, el fundamento, de todos los actos autoritarios (legislativos, ejecutivos y judiciales) tendientes a prevenir o remediar los problemas y calamidades propios de un estado de emergencia, sino la pauta restrictiva de posibles extralimitaciones del poder público dentro de la misma situación de anormalidad. ${ }^{28}$

Es decir, si bien la finalidad perseguida por el procedimiento establecido en el artículo 29 constitucional es permitir que el gobierno haga frente a situaciones de emergencia sin la obstaculización que implica el respeto a determinadas disposiciones constitucionales, no debemos olvidar que el mismo debe realizarse con estricto respeto a las propias normas que lo regulan. Continuaremos dentro de la vigencia de un Estado de derecho. ${ }^{29}$

\section{AUTORIDADES QUE INTERVIENEN EN EL PROCEDIMIENTO DE SUSPENSIÓN DE GARANTÍAS}

La suspensión de garantías es un procedimiento en el que intervienen, en forma conjunta diversas autoridades, a saber: el Ejecutivo federal; los titulares de las secretarías de Estado, de los departamentos administrativos, ${ }^{30}$ y de la Procuraduría General de la República; el Congreso de la Unión y en sus recesos la Comisión Permanente del mismo.

28 Burgoa, I., op. cit., nota 5, pp. 207 y 208.

29 En la suspensión de garantías acaecida en nuestro país en el año de 1942, el entonces Procurador General de la República (que participó en la revisión del decreto relativo y de las leyes de emergencia) indicó: "La circunstancia de que vivamos dentro de un régimen de restricciones de algunas de las garantías individuales, o como más comúnmente se les designa, de suspensión de garantías, no significa, en modo alguno, la ausencia de la norma jurídica, ni el abandono de la vida del derecho y de los principios de ética en que se sustenta...". Véase Aguilar y Maya, José, Breve reseña de la legislación de emergencia expedida en los Estados Unidos Mexicanos, con motivo de su participación en el actual conflicto mundial, incluyendo las leyes y reglamentos formulados por la Procuraduría General de la República y las disposiciones legislativas que con éstos tienen más estrecha relación. Aportación que la Procuraduría General de la República hace, por conducto de su titular, el señor licenciado don José Aguilar y Maya a la Tercera Conferencia de la Federación Interamericana de Abogados, Procuraduría General de la República, México, 1944, p. 9.

30 Dicha disposición es una reminiscencia histórica, dado que actualmente no existen departamentos administrativos del gobierno federal. El último departamento adminis- 
Como se desprende del propio dispositivo constitucional, corresponde al presidente de la República iniciar el procedimiento y, en su momento, decretar la suspensión de garantías.

A los titulares de los órganos indicados de la administración pública federal centralizada, se les faculta para acordar con el Ejecutivo federal el inicio del procedimiento o impedir jurídicamente el mismo.

Al Congreso de la Unión, y en sus recesos a la Comisión permanente del mismo, corresponde la aprobación o negativa a efecto de que el presidente de la República pueda decretar la suspensión de garantías.

Por otra parte, es al Congreso de la Unión y no a la Comisión Permanente al que corresponde otorgar facultades extraordinarias al Ejecutivo de la Unión, en virtud de que dichas facultades se refieren principalmente a la acción legislativa, por lo que en esa medida, la Comisión Permanente no puede delegar facultades que no tiene.

La intervención del Ejecutivo Federal se entiende en la medida en que, dado nuestro sistema constitucional, es a éste a quien corresponde, en términos generales, la administración y ejecución de los actos que rigen al Estado; pero adicionalmente es quien constitucionalmente se espera pueda responder eficaz y ágilmente en virtud de su naturaleza jurídica y facultades (entre otros, es jefe de Estado, administrador económico y máximo comandante de las Fuerzas Armadas), y por lo mismo es el órgano idóneo para hacer frente a las situaciones que puedan generar la suspensión de garantías.

Como contrapeso o control, y dada la trascendencia de la medida, es necesaria la intervención del Congreso de la Unión o su Comisión Permanente.

Algunos autores indican que la intervención de los titulares de los órganos de la administración pública federal centralizada (o Consejo de Ministros, término que anteriormente empleaba nuestra Constitución) es un matiz propio de los Estados parlamentarios; por lo que

...no es "mera reminiscencia histórica" la que como tal se menciona, pues para serlo se necesitaría que la misma hubiera quedado como resto, como supervivencia de un anterior régimen parlamentario, el cual de cierto nunca ha

trativo fue el Departamento del Distrito Federal, cuyo titular, conforme a la entonces Ley Orgánica de la Administración Pública Federal, ostentaba el mismo nivel o rango que los secretarios de Estado. 
existido en México. Se trata... de un matiz parlamentario traído de fuera y que como excepción a nuestro sistema presidencial se utiliza con la finalidad de impedir que el presidente de la República se convierta en un dictador, llegado el caso extraordinariamente grave de suspender las garantías individuales. $^{31}$

Lo que debemos analizar es si realmente la intervención de los titulares de órganos administrativos constituye una restricción para el uso indebido de las facultades presidenciales respecto de la suspensión de garantías. Es decir, si la intervención de éstos en el procedimiento se traduce en un medio de control o contrapeso efectivo al Ejecutivo federal.

Para abordar este aspecto, debemos en primer término definir si la aprobación de los titulares de la administración pública requiere ser unánime o puede ser obtenida mediante mayoría simple. La Constitución no aclara este aspecto.

De la lectura del precepto indicado se advierte que para decretar la suspensión de garantías se requiere el "acuerdo de los titulares", por lo que consideramos que al establecerse distinción, debe entenderse que es requisito sine qua non la unanimidad. A la anterior conclusión se arriba en virtud de que los "titulares" mencionados en el dispositivo constitucional no conforman propiamente un órgano colegiado, sino la coincidencia de diversas autoridades con rangos similares en el mismo procedimiento; es decir, no es una decisión que toma un órgano, sino una medida que adoptan diversas autoridades en lo individual. ${ }^{32}$

Finalmente, por lo que a este aspecto se refiere, consideramos que dada la consecuencia jurídica derivada de dicha decisión, y al no establecer el Constituyente que la misma puede ser tomada por "mayoría simple", la interpretación del precepto de mérito debe ser a favor de la no paralización de la eficacia de normas constitucionales.

Por otra parte, y como se ha indicado en líneas anteriores, dicha intervención es un matiz de tipo parlamentario en virtud de que en estos sistemas de gobierno, el Consejo de Ministros es nombrado por el Parlamento, o en su defecto con aprobación del mismo, por lo que constituye un

31 Tena Ramírez, F., op. cit., nota 17, p. 224.

32 Lo anterior desde luego, no implica que no puedan votar en una misma reunión, o en un mismo momento y lugar, debatiendo con anterioridad el alcance de la medida, pero como mera orientación de la postura personal a adoptar. 
control indirecto de los propios parlamentos respecto del Ejecutivo, mas en nuestro sistema constitucional dicha regla no opera igual, en virtud de que los titulares de las secretarías de Estado son nombrados y removidos libremente por el presidente de la República, por lo que en lógica podría suponerse que en caso de que algún secretario de Estado no estuviera de acuerdo con el Ejecutivo federal en refrendar la solicitud de suspensión de garantías, podría ser destituido, para nombrar a una persona que sí conviniera con dicha propuesta. ${ }^{33}$

Ahora bien, dicho supuesto no opera en forma idéntica tratándose del procurador general de la República, en virtud que por disposición constitucional, si bien puede ser removido libremente por el presidente de la República, el nombramiento del nuevo procurador deberá ser ratificado por el Senado o la Comisión Permanente en los recesos de éste. ${ }^{34}$

\section{CAUSAS GENERADORAS DE SUSPENSIÓN DE GARANTÍAS}

Las causas que pueden dar lugar a una suspensión de garantías no están establecidas en la Constitución en forma limitativa, sino enunciativa. En dicha máxima norma se expresa que la suspensión podrá tener lugar "en los casos de invasión, perturbación grave de la paz pública, o de cualquier otro que ponga a la sociedad en grave peligro o conflicto...”.

33 No pasa desapercibido para el autor, que tal conducta del jefe de Estado puede ser objeto de censura por la opinión pública, pero dicha circunstancia no se traduce en una limitante jurídica.

34 Lo anterior se desprende de los siguientes artículos constitucionales: "Artículo 76. Son facultades exclusivas del Senado... II. Ratificar los nombramientos que el mismo funcionario haga del procurador general de la República...". "Artículo 78. Durante los recesos del Congreso de la Unión... la Comisión Permanente, además de las atribuciones que expresamente le confiere esta Constitución, tendrá las siguientes... V. Otorgar o negar su ratificación a la designación del Procurador General de la República, que le someta el titular del Ejecutivo federal...". “Artículo 89. Las facultades y obligaciones del presidente de la República son las siguientes... IX. Designar, con ratificación del Senado, al procurador general de la República...". "Artículo 102. A... El Ministerio Público de la Federación estará presidido por un procurador general de la república, designado por el titular del Ejecutivo federal con ratificación del Senado o, en sus recesos, de la Comisión Permanente... El procurador podrá ser removido libremente por el Ejecutivo...". 
Ahora bien, debe observarse que salvo el primer caso (el de invasión), ${ }^{35}$ los dos restantes requieren de una decisión discrecional del poder público en la medida en que corresponde a éstos decidir cuándo se considera que el Estado se encuentra en una situación que se traduzca en perturbación grave de la paz pública (con movimientos armados, por ejemplo) o de cualquier otro que ponga a la sociedad en grave peligro o conflicto. Dicha apreciación corresponde observarla a todas las autoridades que intervienen en el procedimiento constitucional que nos ocupa.

En este aspecto, debe observarse que la diversidad de órganos participantes genera un control sobre la discrecionalidad requerida evitando el abuso del procedimiento constitucional, puesto que no bastará la sola apreciación del presidente de la República de haberse actualizado, circunstancia prevista por la norma constitucional; es necesaria además la coincidencia por parte del "gabinete", y más aún, por parte del Congreso de la Unión o su Comisión Permanente.

\section{CONTENIDO DE LA SOLICITUD}

La solicitud de suspensión deberá realizarse mediante prevenciones generales, es decir, tendrá las características de una iniciativa de ley a efecto de que el decreto de suspensión sea una norma jurídica materialmente legislativa. ${ }^{36}$ En dicho contexto, el decreto de suspensión de garantías será una norma jurídica de carácter general, abstracta e impersonal. ${ }^{37}$

En efecto, la suspensión de garantías deberá ser formulada en términos generales, encuadrando en ella todos los casos concretos; y, de igual

35 Entiéndase ésta, la realizada por una potencia extranjera en territorio nacional de forma hostil.

36 Aun cuando en el procedimiento interviene el órgano legislativo, la suspensión de garantías no es una norma formalmente legislativa, en virtud de que el órgano emisor es el Ejecutivo federal. Dicha consideración es, como se observará más adelante, personal del autor y contraria al criterio del máximo órgano de interpretación constitucional del país.

37 Para mayor referencia y explicación de las citadas características de la ley, puede consultarse la jurisprudencia P./J. 18/98 emitida en la Novena Época por el Pleno de la Suprema Corte de Justicia de la Nación, visible en la página 7 del Semanario Judicial de la Federación y su Gaceta, t. VII, marzo de 1998, bajo el rubro: "LEYES PRIVATIVAS. SU DIFERENCIA CON LAS LEYES ESPECIALES". 
forma será impersonal, puesto que no puede ser emitida sólo respecto a determinado individuo o grupo. Lo anterior se desprende claramente del propio artículo 29 constitucional, en la parte que determina que la suspensión debe realizarse mediante "prevenciones generales y sin que... se contraiga a determinado individuo".

Por lo que respecta a la abstracción, ésta se genera en cuanto a que la suspensión de garantías no desaparece por el hecho de aplicarse la norma jurídica. En efecto, no debemos confundir la abstracción de la norma, con el hecho de la desaparición de la misma por agotar su temporalidad o por desaparecer las causas que generaron su emisión. ${ }^{38}$

\section{1. Ámbito personal}

Como se ha indicado, por disposición constitucional la suspensión de garantías no puede contraerse a determinado individuo, debiendo entender por esto, que tampoco podrá referirse en relación a un grupo concreto de individuos. Lo anterior implica también que la norma que determine la suspensión de garantías no puede establecer excepciones personales en su aplicación; es decir, no se puede contraer a determinado individuo, pero tampoco puede dejar fuera de su alcance a individuo o grupo determinado, mientras las garantías individuales de los demás se encuentran suspendidas. ${ }^{39}$

\section{2. Ámbito temporal}

En el documento enviado al Congreso se establecerá el tiempo por el que se solicita la autorización para suspender garantías, en virtud de que dicha suspensión no podrá decretarse por tiempo indefinido de conformidad con el artículo constitucional en estudio.

38 La abstracción de la norma es independiente de la desaparición de conducta a normar. La norma es abstracta cuando la aplicación de ésta hace desaparecer la conducta a normar y, por ende, con ella muere también la norma (por ejemplo, una sentencia de pena de muerte). En el presente caso, la aplicación del decreto no genera que desaparezcan las causas que lo motivaron; es decir, no por hacerse uso de la suspensión de garantías se resolverá, por ese solo hecho, la invasión, perturbación grave o cualquier otro que haya generado la medida.

39 Lo anterior no quiere decir, que por diverso criterio que no sea de ámbito personal, puedan haber personas exceptuadas de la aplicación de la norma, como podría ser porque en el territorio en que se encuentran estas personas no se aplique la medida. 
Una primera interrogante a este respecto es la relativa al tiempo máximo que puede decretarse la suspensión. La norma constitucional no establece límite, puesto que sólo reza que debe decretarse por "tiempo limitado", sin indicar cuál es éste. Lo anterior aumenta el riesgo en que se pone el propio orden constitucional, pues los límites han sido confiados por él mismo a la discrecionalidad de sus autoridades, las que harán depender la temporalidad de la norma del tipo de situación que deben enfrentar. A este respecto podrán operar las normas jurídicas secundarias para delimitar el indicado olvido del Constituyente. ${ }^{40}$

Reiteramos que lo anterior significa una lamentable distracción del Constituyente, puesto que si bien es cierto que la disposición constitucional no debe limitar terminantemente el tiempo de vigencia de la suspensión, puesto que éste debe depender del tiempo en que se encuentre presente la circunstancia que la motiva; también lo es que menor inseguridad jurídica hubiera representado el que la Constitución hubiera limitado el tiempo máximo por el que se conceda la autorización, sin perjuicio de que la misma pueda renovarse indefinidamente hasta que termine la causa que le dio origen.

La reflexión anterior nos lleva a considerar si la solicitud de suspensión de garantías puede volver a realizarse en caso de que el tiempo por el que fue otorgada fenezca sin que se haya resuelto el origen del problema o regresado a la normalidad social prexistente. Concluimos que el Ejecutivo puede iniciar el procedimiento cuantas veces lo estime oportuno, y la norma constitucional encomienda la posibilidad de la misma a la prudencia y discrecionalidad de las autoridades a las que confía la medida.

Otro de los problemas al que nos enfrentamos al analizar la figura jurídica de suspensión de garantías es el relativo a, si una vez desaparecidas las causas que motivaron la misma, ésta debe continuar. Algunos autores consideran que una vez inexistente el estado de emergencia, se produce ipso iure la desaparición de la suspensión de garantías, toda vez que ni el Ejecutivo, ni el Legislativo, ni cualquier autoridad del Estado tiene facultad para retardar dicha cesación. ${ }^{41}$

40 Lo anterior mediante la respectiva emisión legislativa o incluso por la interpretación que el máximo órgano de control constitucional haga del artículo 29 en estudio.

41 Burgoa, I., op. cit., nota 5, p. 214. 
Coincidimos parcialmente con estas opiniones en virtud de que, si han desaparecido las causas que motivaron la medida, la misma de igual forma debe desvanecerse.

De igual forma, si bien las autoridades no tienen facultades para retardar la medida cuando las causas que la originaron han cesado (máxime que lo anterior puede abrir la puerta a la dictadura y a la terminación del Estado de derecho), también debe observarse que el tiempo que debe durar la suspensión se encontrará expreso en las propias disposiciones generales que se decreten, por lo cual, en caso de que cese la causa que originó dicha suspensión y se cumpla el plazo establecido, terminará la vigencia de la misma.

Ahora bien, en caso de que desaparezcan las causas de emergencia y el plazo no haya fenecido, tampoco se puede considerar que la suspensión desaparece por sí sola, en virtud de que es a las propias autoridades a quienes corresponde determinar, en su caso, que las causas que motivaron la suspensión han desaparecido, por lo que se requerirá de una declaración expresa en dicho sentido. Es decir, así como se requirió de un acto jurídico para crear la norma que contiene la suspensión de garantías, de igual forma se requerirá de un acto jurídico para decretar la desaparición de la norma, a no ser que ésta se extinga por sí sola con el agotamiento de la temporalidad con que nació.

En este tenor, se requerirá de un acto discrecional por parte de las autoridades que les permita determinar el regreso a la normalidad en virtud de la cesación de los factores que amenazaron al Estado o a la sociedad.

Asimismo, si hemos advertido que la medida suspensiva puede terminar con anterioridad a la vigencia temporal que le fue impresa, también debemos meditar respecto de las autoridades que participarían en dicho acto.

Una primera reflexión invita a suponer que para decretar la terminación de la norma que estableció la suspensión, deben participar las mismas autoridades que participaron en su creación e incluso, mediante un procedimiento similar. Lo anterior a través de una posible interpretación a contrario sensu de lo expresado por el artículo 29 constitucional, así como en otros artículos por ejemplo el 72, punto f constitucional o diversos que lo armonicen con el conjunto normativo supremo. Sin embargo, considero que para decretar la terminación de la medida, basta con la determinación del presidente de la República. 
En efecto, la suspensión de garantías surge a instancia exclusiva del Ejecutivo, en virtud de que es este poder quien requiere la medida para hacer frente a la circunstancia de riesgo. Como la consecuencia de dicho acto es delicada, dado que implica la alteración de la normalidad jurídica en cuanto a su vigencia y efectividad, la Constitución establece candados importantes para su establecimiento, como el procedimiento, las autoridades que deben participar en el mismo y la forma de su participación. ${ }^{42}$ No obstante, para decretar la desaparición de la suspensión de garantías, bastará con la voluntad y determinación del Ejecutivo, pues será suficiente con que éste considere ya no requerirla, para que la norma no tenga necesidad de subsistencia y, principalmente, porque no podemos admitir que el orden constitucional establezca mayores requisitos que permitan regresar a la normalidad, a la eficacia y su vigencia plena.

\section{3. Ámbito espacial}

La Constitución autoriza la suspensión de garantías, en todo el país o en un lugar determinado, por lo que, en relación con la circunstancia que generó la solicitud, se deberá indicar al Congreso si dicha medida es para suspender las garantías en todo el país, en alguna región del mismo o en determinada entidad o entidades federativas.

Es de suponerse que lo anterior dependerá de la causa que genera la solicitud y, por ende, el lugar en donde se requiera la actuación del gobierno para hacer frente a la misma. ${ }^{43}$

\section{4. Ámbito material}

En las prevenciones generales que contengan la solicitud, se deberán indicar las garantías individuales cuya autorización se solicita para suspenderse, en virtud de que la norma no necesariamente debe abarcar la totalidad de las garantías individuales contenidas en nuestra Constitución para hacer frente a la situación de riesgo. En este punto, debe observarse que todas las garantías individuales son susceptibles de ser suspendidas a

42 En algunos casos con voto aprobatorio indispensable, como en el de los secretarios de Estado.

43 Se estimaría incorrecto, por ejemplo, suspender garantías individuales de personas que se encuentren en una zona que no requiera actuación de gobierno por no encontrarse afectada. 
través de este procedimiento, caso que no ocurría en la Constitución de 1857, puesto que en el procedimiento contenido en dicha carta magna, se establecía la prohibición de suspender las garantías que asegurasen la vida del hombre.

Otro planteamiento que se presente es el relativo a si, el procedimiento establecido en el artículo 29 constitucional puede suspender, al igual que las garantías individuales, otros derechos constitucionales que no sean propiamente garantías individuales, como derechos sociales, garantías sociales o derechos políticos.

A este respecto, consideramos que puede hacerse una interpretación extensiva del artículo 29, y en dado caso se podrán suspender otro tipo de normas constitucionales, siempre y cuando dicha suspensión sea necesaria para hacer frente a la situación de emergencia.

Mención especial merecen en este apartado los derechos políticos, toda vez que, aunque de igual forma podrían restringirse el tiempo que dure la suspensión, la medida debe ser tomada con la correlativa responsabilidad a efecto de evitar el abuso de poder y con ello el sostenimiento del mismo a favor de un dictador que intente prolongarse en el tiempo con apariencia constitucional. $^{44}$

En cualquier caso, la medida del artículo 29 constitucional sólo podrá operar en relación con preceptos de la parte dogmática de la Constitución.

\section{Fundamentación y motivación}

La solicitud deberá indicar los motivos y fundamentos que la originan; es decir, las normas jurídicas que facultan a la autoridad a proponerla, pero también las circunstancias que conllevan al Ejecutivo federal y a su "gabinete" a realizar la misma, indicando no sólo las causas que deben enfrentarse (invasión, perturbación grave de la paz pública, o cualquier otro que ponga a la sociedad en grave peligro o conflicto), sino los moti-

44 A este respecto, Fix Fierro, menciona la opinión consultiva OC-8/87, pfo. 20, de la Corte Interamericana de Derechos Humanos en la que se indica: "La suspensión de garantías carece de toda legitimidad cuando se utiliza para atentar contra el sistema democrático, que dispone límites infranqueables en cuanto a la vigencia constante de ciertos derechos esenciales de la persona", op. cit., nota. 20, pp. 596 y 597. 
vos por los que se considera necesaria la suspensión para hacer frente a las mismas. 45

Lo anterior, no únicamente dará cumplimiento a diversa disposición constitucional (artículo 16), sino que será el motor determinante que lleve al Congreso a autorizar o rechazar la solicitud; guiando en gran medida el debate parlamentario que necesariamente deberá surgir. ${ }^{46}$

\section{Facultades extraordinarias}

Como hemos indicado, el procedimiento previsto en el artículo 29 constitucional tiene como fin la suspensión de garantías, pero también, en relación con ésta, el otorgamiento de facultades extraordinarias a favor del Ejecutivo federal, por lo que la solicitud no sólo será referente a la suspensión, sino también a la concesión de las indicadas facultades.

Ahora bien, en la medida en que dicho otorgamiento de facultades extraordinarias no se refiere a la autorización para suspender garantías, ni a la posibilidad de actuar administrativamente (pues esta facultad ya la tiene el Ejecutivo), se entiende que dicho otorgamiento de facultades refiere en específico la posibilidad de legislar. ${ }^{47}$ Las leyes emitidas por el presiente de la República en estas circunstancias son denominadas: leyes de emergencia.

"El sentido de toda Constitución racional es procurar un sistema de organización que permita formar una voluntad política e instruir un gobierno capaz de gobernar". ${ }^{48}$ Ante las situaciones previstas por el artículo 29 constitucional, la voluntad política se contendrá en gran medida en una sola autoridad que pueda hacer frente a las circunstancias que motivan el estado de excepción, permitiéndole legislar y aplicar administrativamente las propias normas.

45 Desde luego que con lo anterior, también deberán expresarse las razones que sustenten el tiempo por el que se solicita la medida y el territorio en el cual aplicará.

46 Adicionalmente, será parte de la legitimación de la medida ante la opinión pública.

47 El hecho de otorgar facultades extraordinarias es para ejercer la función legislativa es observado por diversos autores, entre los que se citan a Burgoa, Ignacio, Derecho constitucional mexicano, 9a. ed., México, Porrúa, 1994, p. 778. De igual forma Valadés, Diego, Constitución y Política, 2a. ed., México, UNAM, Instituto de Investigaciones Jurídicas, 1994, p. 196.

48 Schmitt, Carl, La defensa de la Constitución, 2a. ed., trad. de Manuel Sánchez Sarto, Madrid, Tecnos, 1998, p. 188. 
En este aspecto, es importante no confundir el decreto de suspensión con el otorgamiento de facultades extraordinarias, puesto que son actos diversos. Más aún, es jurídicamente posible que el Congreso autorice al Ejecutivo la suspensión de garantías, pero le niegue el otorgamiento de facultades extraordinarias. ${ }^{49}$

Por otra parte, un análisis requerido respecto del otorgamiento de facultades extraordinarias es el relativo a si las autorizaciones que se otorguen al Ejecutivo por el Congreso de la Unión permiten la creación de leyes que, además de hacer caso omiso a los derechos fundamentales suspendidos, vayan en forma directa contra algún principio o precepto constitucional que no constituya propiamente una garantía individual. Es decir, la cuestión a dilucidar es si al momento en que el presidente emita las leyes necesarias para hacer frente a la crisis, además de hacer caso omiso a las garantías suspendidas, puede violentar normas constitucionales diversas, por ejemplo, atribuyéndose facultades para juzgar o subordinar las autoridades estatales y municipales a las federales.

Para responder a lo anterior, indicaremos que las autorizaciones deben ir en estrecha relación con la suspensión de garantías y respetar los principios constitucionales existentes, como, en este caso, la división de poderes o la estructura del Estado federal, puesto que lo anterior sale de la órbita de una mera suspensión de garantías. Llegar a tal extremo, sería aceptar que por la aplicación de la medida suspensiva, se podría dejar sin efecto alguno la vigencia (aunque en forma temporal) de la norma fundamental; es decir, el artículo 29 constitucional se podría convertir en un "hoyo negro" por el que se vaciara la totalidad del régimen constitucional.

En dicho tenor, consideramos que la autorización de suspensión de garantías y el otorgamiento de facultades para legislar, no debe implicar el quebrantamiento de principios constitucionales diversos ${ }^{50}$ que no son

49 Aunque la autorización para la suspensión de garantías y el otorgamiento de facultades extraordinarias sean diversos, ambos pueden resolverse conjuntamente y contenerse en el mismo acto legislativo.

50 La ley de Prevenciones Generales Relativas a la Suspensión de Garantías establecida por Decreto del 1o. de junio de 1942, publicada en el Diario Oficial de la Federación del 13 de junio de 1942, en su artículo 16 estableció: "La suspensión de la garantía consignada en el párrafo primero del artículo 21 de la Constitución, radica en la facultad del Ejecutivo federal para imponer las penas que la legislación de emergencia le enco- 
materia de la disposición constitucional contenida en el artículo 29 del pacto federal.

De igual forma, las leyes de emergencia deben encontrar su finalidad en la propia finalidad de la suspensión de garantías; es decir, su contenido debe ir encaminado a afrontar la situación que generó la medida constitucional que nos ocupa. ${ }^{51}$

Otro aspecto a considerar es el relativo a la validez y vigencia de las leyes de emergencia una vez que ha cesado la suspensión de garantías.

En este sentido, al quedar sin efectos la suspensión de garantías decretada por la situación de emergencia, se restablece el orden constitucional en toda su plenitud, quedando sin efectos las prevenciones generales y de igual forma las leyes expedidas por el Ejecutivo federal en uso de las facultades extraordinarias conferidas. ${ }^{52}$

En dicho tenor, la validez y vigencia de las leyes de emergencia deriva del decreto de suspensión de garantías, por lo que al perder eficacia este último, de igual forma la pierden las primeras.

No obstante lo indicado en el párrafo precedente, el Congreso de la Unión en uso de su facultad legislativa puede hacer suyas las leyes emitidas durante la vigencia de la suspensión de garantías, aprobándolas e incorporándolas a la legislación ordinaria. En este caso, se deberá seguir por el órgano legislativo el procedimiento establecido en la Constitución para la creación de leyes, y su resultado será la emisión de las mismas, independientemente de que su contenido coincida con el que en su momento tuvieron las leyes de emergencia. ${ }^{53}$

miende". Como indicamos, esta disposición hoy en día resultaría, desde nuestro punto de vista, contraria a la Constitución.

51 Cfr. Burgoa, Ignacio, La legislación de emergencia y el juicio de amparo, México, Hispano-Mexicana, 1945, p. 62.

52 Cfr. Castro, Juventino, Garantías y amparo, 8a. ed., México, Porrúa, 1994, p. 214.

53 Algunas leyes de emergencia emanadas de la última aplicación del artículo 29 constitucional, fueron incorporadas a la legislación ordinaria mediante decreto del 28 de septiembre de 1945, sin que lo anterior implicara la subsistencia de las citadas leyes de emergencia, y menos aún la extensión de la suspensión de garantías. Respecto de lo anterior, véase entre otras, la tesis sustentada en la Séptima Época por el Pleno de la Suprema Corte de Justicia de la Nación, visible en la página 36 del Semanario Judicial de la Federación, 68 Primera Parte, bajo el rubro: "LEYES DE EMERGENCIA. INCORPORACIÓN A LA LEGISLACIÓN ORDINARIA". De igual forma, puede observarse la tesis emitida en la Sexta Época por el Pleno de la Suprema Corte, página 228 del Semanario Judicial de la Federación, primera parte, t. XXXVII, intitulada: "LEYES DE 
Finalmente en cuanto a este punto refiere, es conveniente mencionar que la suspensión de garantías no genera competencia para que las autoridades locales puedan actuar en forma similar a las federales ${ }^{54}$ respecto de facultades extraordinarias. Es decir, si bien es cierto que al suspenderse las garantías individuales, dicha medida no sólo surte efectos para las autoridades federales, sino también para las locales, dado que estas últimas podrán actuar sin las limitantes previstas en las normas constitucionales suspendidas, ${ }^{55}$ también lo es que la misma no implica que las autoridades locales puedan desobedecer el principio de división de poderes establecido en la Constitución y, por ende, no están facultadas a otorgar facultades extraordinarias a favor de autoridad alguna, como podría ser el gobernador del estado, así como tampoco podrán actuar desobedeciendo principios constitucionales diversos. Lo anterior además de que la suspensión de garantías no implica la suspensión o inobservancia de los ordenamientos jurídicos locales, por lo que dichas autoridades deberán continuar actuando en estricto apego a sus normas mientras éstas se encuentren vigentes. ${ }^{56}$

EMERGENCIA. CONSTITUCIONALIDAD DE SU INCORPORACIÓN A LA LEGISLACIÓN ORDINARIA". También resulta claro el criterio sustentado por la Suprema Corte, en la página 120 del Semanario Judicial de la Federación, 97-102 primera parte, bajo el rubro: "LEYES DE EMERGENCIA, RATIFICACIÓN DE LAS, POR EL CONGRESO. NO CONTRARÍA MANDATO CONSTITUCIONAL ALGUNO".

54 Que en estos casos, como lo indicamos, no actúan como autoridades federales sino como órganos del orden constitucional o total.

55 Así, los congresos locales podrán emitir leyes secundarias que no observen las limitantes contenidas en las garantías individuales suspendidas, y que, por ende, con fundamento en dichas normas las autoridades locales en general podrán realizar actos autoritarios que en tiempos regulares no serán válidos a la luz del derecho, ameritando una declaratoria de inconstitucionalidad.

56 A este respecto, la Segunda Sala de la Suprema Corte de Justicia de la Nación emitió la tesis 2467, visible a página 1715 del apéndice 2000, t. I, o a página $2146 \mathrm{del} S e-$ manario Judicial de la Federación, Quinta Época, t. LXXXVI, bajo el rubro: "RENTAS DE VIVIENDAS, PROHIBICIÓN DEL AUMENTO DE LAS (DECRETO 129 LEGISLACIÓN DE COAHUILA)", en la que estableció un criterio en el sentido de que la suspensión de garantías es materia reservada a las autoridades federales. Consideramos que las garantías suspendidas no obligarán a su respeto a las autoridades federales, pero tampoco a las locales, pues su eficacia ha sido suspendida, sin que lo anterior implique la desobediencia de las garantías no suspendidas, y menos aún el desconocimiento de los principios constitucionales, como el de división de poderes entre otros, el que sólo se altera respecto del otorgamiento del uso de facultades extraordinarias, cuyo caso es exclusivo de las autori- 


\section{DESARROLLO DEL PROCEDIMIENTO CONSTITUCIONAL}

Como hemos indicamos, el único facultado para iniciar el procedimiento de suspensión de garantías es el Ejecutivo federal, para lo cual deberá contar con el acuerdo de todos y cada uno de los servidores públicos de la administración pública federal centralizada indicados en el propio artículo 29 constitucional. Una vez obtenido dicho acuerdo, se remitirá al Poder Legislativo federal la solicitud respectiva para su autorización o rechazo.

La aprobación del Legislativo por lo que hace a la suspensión de garantías, se realizará por el Congreso General en caso de encontrarse reunido, o por la Comisión Permanente del mismo en sus recesos. Sin embargo, por lo que hace al otorgamiento de las facultades extraordinarias a favor del Ejecutivo federal, única y exclusivamente compete al Congreso y no así a la Comisión Permanente, puesto que las mismas serán facultades para legislar y, en tal virtud, la Comisión permanente no puede decidir respecto de una facultad que no posee. ${ }^{57}$

Ahora bien, la Constitución no refiere la forma en que el Congreso de la Unión debe desplegar su actividad en estos casos. La Ley Orgánica del Congreso en su artículo 5o., establece los casos en los que éste se reunirá en sesión conjunta de ambas cámaras y en dicha disposición no se encuentra el supuesto del artículo 29 constitucional, lo que indica que la aprobación del Congreso de la solicitud de suspensión de garantías (en caso de que éste se encuentre reunido) y del otorgamiento de facultades extraordinarias, deberá hacerse en forma sucesiva en cada una de las cámaras.

Consideramos que lo anterior es un lamentable olvido del legislador federal, toda vez que dada la importancia y premura con que se debe de llevar a cabo el procedimiento en estudio, sería conveniente que el Congreso resolviera en sesión conjunta y no dilatar el procedimiento a través de sesiones sucesivas de las cámaras.

dades federales, por aplicación del artículo 29 constitucional, mientras que las autoridades locales no encuentran sustento jurídico alguno.

57 La Comisión Permanente del Congreso de la Unión no legisla, por lo que la autorización al Ejecutivo para que éste desarrolle dicha actividad sólo concierne al órgano que originalmente la ostenta. 
Obsérvese que por lo que hace a la suspensión de garantías, en casos de urgente premura, pareciera más eficaz que el Congreso se encuentre en receso, puesto que la Comisión Permanente resolvería en una sola sesión. Desde luego que consideramos que ésta no es la finalidad de la disposición constitucional.

Por diversa parte, la Constitución no establece si el Congreso puede realizar observaciones a la solicitud; sin embargo, debemos entender que la autorización para decretar la suspensión de garantías puede contener las mismas y no limitar la autorización del Congreso (o de la Comisión) a su sola aprobación o rechazo, puesto que sería inadecuado suponer que por no permitirse las citadas observaciones, en un caso de emergencia, se tuviera que negar la misma.

En otro contexto, diversos autores coinciden en que la suspensión de garantías sólo puede ser decretada por el Congreso de la Unión al aprobar la iniciativa del presidente de la República. ${ }^{58}$ Similar consideración ha realizado la Suprema Corte de Justicia de la Nación. ${ }^{59}$

Considero inadecuada la citada interpretación. De conformidad con el artículo 29 constitucional, es únicamente al presidente de la República a quien corresponde decretar la suspensión de garantías, sin que para ello se niegue que a tal efecto deba contar con el acuerdo de su gabinete para solicitar al Congreso federal la autorización de realizar tal acto. Es decir, de acuerdo con el citado dispositivo constitucional, "solamente el presidente de los Estados Unidos Mexicanos... podrá suspender... las garantías", siendo diferente el hecho consistente en que para lo anterior, deba contar con la aprobación del Congreso o Comisión Permanente, puesto que dicha aprobación del Legislativo no hace suya la suspensión, sino que precisamente aprueba la conducta que intenta el Ejecutivo.

Si bien es cierto que la suspensión de garantías se llevará a cabo mediante la emisión de una norma general (similar a la ley), la misma no es emitida por el Congreso, sino por el presidente de la República con aprobación del Congreso. De esta forma, aun cuando el procedimiento del ar-

58 Entre otros, se citan, Tena Ramírez, F., op. cit., nota 17, p. 220. Carpizo, Jorge, Estudios constitucionales, 2a. ed., México, UNAM, Instituto de Investigaciones Jurídicas, 1983, p. 333; id., La Constitución mexicana de 1917, 11a. ed., México, Porrúa-UNAM, Instituto de Investigaciones Jurídicas, 1998, p. 284.

59 A este respecto puede observarse la tesis emitida en la Quinta Época por la Tercera Sala de la Suprema Corte de Justicia de la Nación, visible a página 839 del apéndice 2000, t. I, cuyo rubro indica: GARANTÍAS INDIVIDUALES, SUSPENSIÓN DE LAS. 
tículo 29 constitucional tenga grandes semejanzas con el procedimiento de creación de leyes, no es el mismo, y por lo tanto tiene sus características propias.

En efecto, el procedimiento constitucional es iniciado mediante un acto de competencia exclusiva del Ejecutivo, por ser éste el órgano de gobierno que requiere la medida para actuar en defensa del Estado o la sociedad en forma enérgica y eficaz; pero de igual forma es éste el único autorizado para decretar la medida.

Así pues, el acto mediante el cual el Congreso (o su Comisión Permanente) resuelve otorgar la autorización al Ejecutivo para suspender garantías individuales, no es en sí mismo el decreto que suspende las garantías, sino simplemente la autorización a efecto de que el presidente de la República decrete dicha suspensión, lo que en su caso hará mediante acto diverso y posterior al del Congreso, culminando con éste el procedimiento constitucional.

La anterior interpretación permite concluir además, que incluso el Ejecutivo Federal está en posibilidad jurídica de no decretar la suspensión de garantías, no obstante haber sido autorizado para ello por el Congreso de la Unión, culminando de igual forma con dicho acto el procedimiento constitucional respectivo.

Los razonamientos expresados en líneas anteriores no operan tratándose del otorgamiento de facultades extraordinarias, puesto que éstas son decretadas desde luego, única y exclusivamente, y en un solo acto, por el Congreso de la Unión.

Por otra parte, aun cuando la Constitución no establezca algo al respecto, diverso razonamiento nos lleva a considerar la necesaria la publicación de la medida suspensiva en el periódico de difusión oficial para conocimiento de los gobernados y autoridades del país. No obstante lo indicado, consideramos que a diferencia de lo que ocurre con las leyes ordinarias, la publicación del decreto de suspensión de garantías no es requisito indispensable para su vigencia, pues ésta la obtiene por su sola emisión, sin que lo anterior implique la inexistencia de la obligación de publicar la norma.

Finalmente, sostenemos que una vez iniciado el procedimiento constitucional, no podrán variarse los ámbitos de validez que el Ejecutivo propuso tuviera la norma suspensiva. Es decir, si con posterioridad al acuerdo con los integrantes de la administración pública de la medida para 
suspender determinadas garantías, por tiempo específico o en territorio delimitado, el Ejecutivo considerara de igual forma necesaria la suspensión de garantías diversas a las consideradas en primer término, con temporalidad distinta o en territorio adicional, se requerirá de nuevo procedimiento en términos del artículo 29 constitucional. Lo anterior es así, dado que cada aspecto de la suspensión de garantías debe ser sometido al cumplimiento cabal e irrestricto del procedimiento establecido en la norma suprema. ${ }^{60}$

\section{TRATADOS INTERNACIONALES}

Los derechos fundamentales son normas jurídicas de relevancia para el derecho internacional, que las incorpora en diversos instrumentos formando un sólido cuerpo de derecho internacional de derechos del hombre. ${ }^{61}$

El Estado mexicano ha suscrito y ratificado compromisos internacionales como el Pacto Internacional de Derechos Civiles y Políticos y la Convención Americana Sobre Derechos Humanos; las que requieren mención especial por contener disposiciones relacionadas con el presente tema.

En el artículo 4o. del Pacto Internacional de Derechos Civiles y Políticos se establece:

1. En situaciones excepcionales que pongan en peligro la vida de la nación y cuya existencia haya sido proclamada oficialmente, los Estados partes en el presente Pacto podrán adoptar disposiciones que, en la medida estrictamente limitada a las exigencias de la situación, suspendan las obligaciones contraídas en virtud de este Pacto, siempre que tales disposiciones no sean incompatibles con las demás obligaciones que les impone el derecho internacional y no entrañen discriminación alguna fundada únicamente en motivos de raza, color, sexo, idioma, religión u origen social.

2. La disposición precedente no autoriza suspensión alguna de los artículos 6o., 7o., 8o. (párrafos 1 y 2), 11, 15, 16 y 18.

60 Lo anterior acontecerá de igual forma tratándose de la obtención de prórroga en caso de agotarse la temporalidad del decreto de suspensión, sin poder obviarse trámite alguno contenido en el dispositivo constitucional.

61 Cfr. Herrendorf, Daniel, El poder de policía en un sistema de derechos humanos, México, Instituto Nacional de Ciencias Penales, 1990, pp. 287 y 288. 
3. Todo Estado parte en el presente Pacto que haga uso del derecho de suspensión deberá informar inmediatamente a los demás Estados partes en el presente Pacto, por conducto del secretario general de las Naciones Unidas, de las disposiciones cuya aplicación haya suspendido y de los motivos que hayan suscitado la suspensión. Se hará una nueva comunicación por el mismo conducto en la fecha en que se haya dado por terminada tal suspensión.

Del texto transcrito se desprende que los artículos 6o. (respeto a la vida), 7o. (prohibición de tortura o penas crueles), 8o. (prohibición de esclavitud y servidumbre), 11 (prohibición de encarcelamiento por deudas de carácter civil), 15 (Prohibición de retroactividad de normas penales), 16 (reconocimiento de la personalidad jurídica) y 18 (libertad de pensamiento y religión) del mismo ordenamiento jurídico, no serán susceptibles de suspenderse bajo ninguna circunstancia.

Por su parte, en el artículo 27 de la Convención Americana Sobre Derechos Humanos se determina:

1. En caso de guerra, de peligro público o de otra emergencia que amenace la independencia o seguridad del Estado parte, éste podrá adoptar disposiciones que, en la medida y por el tiempo estrictamente limitados a las exigencias de la situación, suspendan las obligaciones contraídas en virtud de esta Convención, siempre que tales disposiciones no sean incompatibles con las demás obligaciones que les impone el derecho internacional y no entrañen discriminación alguna fundada en motivos de raza, color, sexo, idioma, religión u origen social.

2. La disposición precedente no autoriza la suspensión de los derechos determinados en los siguiente's artículos: 30 . (derecho al reconocimiento de la personalidad jurídica); 4o. (derecho a la vida); 5o. (derecho a la integridad personal); 6o. (prohibición de la esclavitud y servidumbre); 9o. (principio de legalidad y de retroactividad); 12 (libertad de conciencia y de religión); 17 (protección a la familia); 18 (derecho al nombre); 19 (derechos del niño); 20 (derecho a la nacionalidad), y 23 (derechos políticos), ni de las garantías judiciales indispensables para la protección de tales derechos.

3. Todo Estado parte que haga uso del derecho de suspensión deberá informar inmediatamente a los demás Estados partes en la presente Convención, por conducto del secretario general de la Organización de los Estados Americanos, de las disposiciones cuya aplicación haya suspendido, de los motivos que hayan suscitado la suspensión y de la fecha en que haya dado por terminada tal suspensión. 
En la disposición internacional indicada, de igual forma se advierte que sus artículos 3o. (reconocimiento de la personalidad jurídica), 4o. (derecho a la vida), 5o. (derecho a la integridad personal), 6o. (prohibición de esclavitud y servidumbre), 9o. (principio de legalidad y de retroactividad), 12 (libertad de conciencia y de religión), 17 (protección a la familia), 18 (derecho al nombre), 19 (derechos del niño), 20 (derecho a la nacionalidad) y 23 (derechos políticos), así como garantías judiciales indispensables para la protección de tales derechos, no son susceptibles de ser suspendidos en momento alguno.

En este contexto y como se indicó con anterioridad, el Estado mexicano ha suscrito dichos instrumentos que han pasado a formar parte integral del derecho interno, tal pareciera que la actuación de las autoridades en aplicación del artículo 29 constitucional se encuentra aún más acotada de lo dicho hasta el momento en el presente trabajo. Sin embargo, consideramos que dichas disposiciones del Pacto Internacional de Derechos Civiles y Políticos y la Convención Americana Sobre Derechos Humanos no son acordes a la Constitución.

A dicho razonamiento llegamos en virtud de que el artículo 29 constitucional no establece limitante alguna en relación con las garantías individuales susceptibles de ser suspendidas, por lo que la medida puede llevarse a cabo respecto a todas sin excepción, sin que sea obstáculo desde luego una disposición contenida en una norma jerárquica inferior al precepto del pacto federal de nos ocupa.

En efecto, conforme con nuestro ordenamiento jurídico, los instrumentos internacionales son inferiores a la Constitución y por lo tanto no pueden establecer limitantes a la misma o contradecirla. ${ }^{62}$

En dicho tenor, si el artículo 29 constitucional faculta a las autoridades a suspender la totalidad de las garantías individuales, no puede válidamente una norma jurídica inferior contradecir tal precepto, estableciendo que no todas las garantías individuales son susceptibles de suspenderse.

Ahora bien, una vez determinado que los instrumentos internacionales citados no son acordes con la Constitución, es necesario analizar si no obstante lo anterior su aplicación es obligatoria por parte de las autoridades federales.

62 Lo anterior se reafirma por diversos criterios jurisprudenciales de los órganos de control constitucional del Poder Judicial de la Federación, pero también con el contenido de los artículos 15, 105 frac. II, incisos b), c) y g) y 107 frac. VIII, inciso a), entre otros. 
Lo anterior en virtud de que: a) son normas jurídicas obligatorias para las autoridades federales, b) la contradicción de una norma inferior respecto de una superior no autoriza a su desaplicación salvo que así sea decretada por el órgano de control competente y, c) aunque en nuestro sistema se acepta la relación jerárquica normativa, respecto a la aplicación de las normas dicha predominancia opera a la inversa. En efecto, la autoridad está obligada a aplicar la norma inferior e inmediata ante la imposibilidad e incompetencia jurídica para poder determinar su inconstitucionalidad.

No obstante lo dicho y como indicamos en el punto II.2 del presente trabajo, el procedimiento contenido en el artículo 29 de mérito se desarrolla dentro del orden constitucional o total y, por ende, las autoridades u órganos que en el mismo actúan lo hacen investidas de la misma naturaleza (como órganos constitucionales). Sostenemos que en virtud de lo anterior, éstas pueden desarrollar el procedimiento aplicando directamente la norma constitucional y haciendo caso omiso de cualquier precepto diverso que contradiga o limite la facultad que el propio dispositivo establece. 63

\section{CONTROL CONSTITUCIONAL}

El procedimiento contenido en el artículo 29 constitucional tiene la finalidad de suspender las garantías individuales otorgadas por la norma suprema. En conexión con lo anterior, es necesario cuestionarse sobre la procedencia de controles constitucionales respecto de dicha medida también constitucional. ${ }^{64}$

En efecto, conforme a la naturaleza jurídica que hemos observado de las garantías individuales en el presente trabajo, la existencia (o proce-

63 Igual consideración opera en casos análogos, como podría ser el procedimiento de reforma constitucional, respecto del cual no podemos sostener que las autoridades federales o locales (Constituyente Permanente o Poder Revisor de la Constitución) al desarrollar el mismo puedan encontrarse limitadas materialmente a plasmar determinado contenido constitucional por prohibición de norma jurídica secundaria y, por lo mismo, inferior.

64 Alguno autores rechazan en forma contundente y absoluta la idea del control constitucional vía amparo, controversia constitucional o acción de inconstitucionalidad. Véase Arteaga Nava, Elisur, Derecho constitucional, 2a. ed., México, Oxford, 1999. p. 601. 
dencia) de medios de control constitucional sobre los actos derivados de la aplicación del artículo 29 constitucional se transforma, más que en una defensa efectiva de los derechos de los gobernados, en un medio de defensa de la Constitución mediante el cual se hace respetar a ésta frente a los actos del poder público engendrados por ella misma.

Uno de los principales aspectos de la idea de constitucionalismo es la existencia de controles sobre normas generales, ${ }^{65}$ incluidas en éstas la que se emite mediante la declaratoria de suspensión de garantías. El origen de la jurisdicción constitucional es la defensa de la Constitución respecto del ordenamiento jurídico secundario; pero más allá, algunos autores consideran que debemos observar a los órganos de control constitucional como verdaderos guardianes de la norma fundamental, que deben ampliar su ámbito de control respecto de todo acto o suceso que vulnere la norma suprema, ${ }^{66}$ y que donde no hay control, no sólo se debilita la Constitución, sino que simplemente no hay Constitución. ${ }^{67}$ El control deberá representar pues, un elemento definidor que permita observar al derecho (y no a la fuerza) como el fundamento del poder. ${ }^{68}$

\section{Amparo}

Lo anterior nos lleva a analizar si en un caso de suspensión de garantías individuales seguiría operando el juicio constitucional de amparo, que tiene como finalidad la defensa de los derechos fundamentales otorgados por la Constitución. Precisamente, con las mismas normas que el procedimiento en estudio suspende, se despoja temporalmente de su eficacia.

Creemos necesario observar primeramente, si en su caso el decreto relativo suspende todas las garantías individuales existentes o si se limita a suspender sólo algunas de ellas, dejando intocadas otras restantes.

Parece claro que en el segundo caso, el amparo deberá seguir desarrollándose en sus causes normales por lo que respecta a la defensa de las garantías individuales que no fueron suspendidas.

65 Troper, M., citó: Prieto Sanchís, Luis, Constitucionalismo y positivismo, México, Fontamara, 1997, p. 15.

66 Cfr. De Vega García, Pedro, Estudios político constitucionales, México, Instituto de Investigaciones Jurídicas-UNAM, 1987, p. 300.

67 Aragón, M., citó: Prieto Sanchís, Luis, op. cit., nota 65, p. 16.

68 Matteucci, N., citó: Idem. 
La interpretación que en su momento otorgó el Ejecutivo de la Unión en la época de suspensión de garantías dada en nuestro país dentro del marco de la actual Constitución, fue la de considerar la improcedencia del juicio de amparo en contra de leyes o actos derivados de la suspensión de garantías, sin importar que éstos fueran violatorios de garantías individuales no suspendidas.

En efecto, el artículo 18 de la Ley de Prevenciones Generales Relativa a la Suspensión de Garantías establecida por Decreto del 1o. de junio de 1942, publicada en el Diario Oficial de la Federación del 13 de junio de 1942, determinó:

Artículo 18. No se dará entrada a ninguna demanda de amparo en que se reclame alguna disposición de las leyes de emergencia o algún acto derivado de las mismas.

Cuando se hubiere admitido alguna demanda en que se de apariencia diversa al acto reclamado, deberá sobreseerse el juicio tan luego como se tenga conocimiento a virtud de informe de autoridad federal, de que tal acto se encuentre fundado en la presente ley. En tal caso, si se hubiere dictado auto de suspensión provisional o definitiva, se revocará de plano y sin recurso alguno.

Como se desprende, se decretó la improcedencia del amparo, no respecto de garantías individuales suspendidas, sino respecto de leyes de emergencia o actos derivados de las mismas independientemente de la garantía cuyo reclamo de violación fuera realizado. Es decir, lo determinante no era la garantía que se consideraba vulnerada (observando si estaba suspendida o no), sino el acto vulnerador de la misma.

Sin embargo, en virtud de los razonamientos arriba contenidos consideramos jurídicamente indebido lo anterior. Si existen garantías no suspendidas, el reclamo de su violación debe ser procedente mediante el juicio constitucional de amparo. Por el contrario, será correcto determinar la improcedencia del amparo respecto de reclamos por violación de garantías que se encuentren suspendidas.

Ahora bien, más allá de la posibilidad de impugnar en amparo las violaciones a derechos fundamentales no suspendidos, emerge la posibilidad de reclamar vía el propio juicio constitucional, el procedimiento del cual derivó la suspensión de garantías. 
En efecto, consideramos que, previo ejercicio de la respectiva acción, el órgano de control tendrá la posibilidad de analizar si el procedimiento que culminó con el decreto suspensivo respetó íntegramente el contenido del artículo 29 constitucional. Es decir, si el procedimiento está regulado en el artículo 29 de la norma suprema, luego entonces debe apegarse a ésta, y en ese sentido podrá estribar el análisis constitucional, dado que "no puede considerarse válida... una ley que no ha nacido conforme a lo establecido en la Constitución...". ${ }^{69}$ Así, tanto el procedimiento como el decreto de suspensión de garantías deberán encontrarse en estricto apego al texto constitucional so pena de declaración de inconstitucionalidad.

En este sentido, el órgano de control podrá analizar no sólo las cuestiones formales del procedimiento, sino de igual forma los aspectos materiales del decreto que determina la suspensión de garantías. Es decir, el órgano de control constitucional podrá entrar al estudio del acto para observar que éste haya cumplido con establecer una temporalidad acorde con lo que ordena el dispositivo constitucional, o que no se haya contraído a determinado individuo o grupo. Más allá, sostenemos que en determinada medida y dependiendo el caso, el órgano judicial podrá analizar: a) si la suspensión de determinadas garantías en específico era realmente la idónea para hacer frente a la situación, es decir, si no se suspendieron garantías cuyo ejercicio no imposibilitaba una actuación eficaz para hacer frente al estado de emergencia; b) si las circunstancias que motivaron la medida existen, c) si el territorio en el cual se suspendieron las garantías individuales se encuentra afectado o en peligro por las circunstancias que impulsaron el decreto, etcétera. ${ }^{70}$

69 Silva, Gustavo de, "El cumplimiento de disposiciones constitucionales en el procedimiento legislativo", en Calvo, Enrique (coord.), Propuesta de reformas legales e interpretación de las normas existentes, México, Barra Mexicana, Colegio de Abogados, Themis, 2002, t. I, p. 1229.

70 Parece claro que en determinados casos el decreto puede contener elementos que, aunque previstos en la norma, sean en el supuesto específico ajenos a la finalidad que busca la medida constitucional. En cualquier caso, lo anterior siempre admitirá la crítica de que éstas fueron decididas discrecionalmente por el Ejecutivo, pero considero que lo anterior no debe impedir el análisis del órgano constitucional, principalmente en casos en que las circunstancias de la realidad son evidentes en no permitir sostener dicho ejercicio discrecional con un mínimo de coherencia. Sólo a modo de ejemplo, podría alegarse en juicio la inconstitucionalidad de suspender garantías en el territorio del estado de Tabasco, en virtud de una catástrofe natural acaecida en el Baja California, principalmente si el 
Al obtenerse el amparo en contra del decreto que establece la suspensión de garantías, se desencadenará en igual medida la inconstitucionalidad de las leyes de emergencia y actos violatorios incluso de las garantías que fueron suspendidas. En efecto, en la medida en que se declare la inconstitucionalidad del decreto suspensivo, se tornarán inconstitucionales las leyes de emergencia, puesto que éstas se apoyan en un otorgamiento de facultades extraordinarias que ha perdido su justificación; pero de igual forma, se estará en posibilidad de velar por el respeto a las garantías individuales suspendidas, dado que en virtud de la protección constitucional su efectividad ha dejado de ser contenida. ${ }^{71}$

\section{Controversia constitucional}

Aspecto diverso pero no de menor importancia es analizar si el decreto de suspensión de garantías puede ser sometido a un control constitucional diverso, como puede ser el previsto en la fracción I del artículo 105 de la norma suprema: las controversias constitucionales.

Consideramos que lo anterior será posible en la medida en que el órgano de control (en este caso la Suprema Corte de Justicia de la Nación) reconozca en el órgano con legitimación activa, interés para combatir un decreto que suspende garantías individuales de gobernados. En efecto, únicamente los órganos previstos en dicha fracción I del artículo 105 constitucional podrán demandar ante la Corte, pero será necesario que ésta resuelva si el órgano respectivo tiene interés en combatir un acto que afecta la esfera jurídica de gobernados (puesto que éstos son los titulares de las garantías individuales suspendidas), y no así de órganos gobernantes (como sería el caso del actor).

decreto de suspensión no se refirió a todo el país, sino únicamente a estos dos estados, y no funda ni motiva adecuadamente su determinación.

71 Lo anterior no será ajeno a complicaciones de índole diversa, como las relativas al interés jurídico o a la naturaleza de la norma jurídica suspensiva de garantías, en cuanto a si el decreto genera agravio por su sola entrada en vigor (autoaplicativo) o si es menester de un acto posterior que actualice el mismo (heteroaplicativa), dado que en caso de que los órganos del Poder Judicial de la Federación determinen que el decreto es heteroaplicativo, se deberá esperar a que se genere una violación a una garantía individual suspendida para estar en posibilidad de acudir al juicio de amparo; en caso contrario, se podrá acudir al órgano constitucional desde la entrada en vigor del decreto. 
En cualquier caso, consideramos que el medio de defensa constitucional será procedente en el supuesto de que el decreto de suspensión o las leyes de emergencia derivadas de éste, invadan la competencia otorgada por la carta magna al órgano o entidad que ejerza la acción.

\section{Acción de inconstitucionalidad}

Finalmente debemos dilucidar la procedencia de la acción de inconstitucionalidad prevista en la fracción II del artículo 105 constitucional.

Como ya hemos indicado, el decreto mediante el que se suspenden las garantías individuales es una norma general, abstracta e impersonal. En tal virtud se cubre el supuesto indicado en el primer párrafo de la citada fracción II; sin embargo, deberá ser la Corte la que en su momento otorgue o no una amplia interpretación a los términos empleados en los incisos respectivos, en los que al mencionar los tipos de normas que pueden ser impugnadas, refiere específicamente a leyes o tratados internacionales. ${ }^{72}$

En caso de salvar lo anterior, queda advertir que conforme el actual criterio de la Suprema Corte de Justicia de la Nación, el decreto de sus-

72 Lo anterior, en virtud de que los incisos de la fracción II del artículo 105 constitucional refieren específicamente a leyes o tratados internacionales, por lo que una interpretación rigorista no permitiría impugnar por esta vía el decreto de suspensión de garantías, puesto que aun siendo una norma general, no es propiamente una ley o tratado internacional. Sin embargo, la Suprema Corte ha interpretado que existen normas jurídicas que al compartir la misma naturaleza que las leyes, son consideradas igual que tales en los procesos constitucionales previstos en el artículo 105 constitucional. Para lo anterior puede verse el criterio sustentado en la jurisprudencia P./J. 23/99 sustentada en la Novena Época por el Pleno de la Suprema Corte de Justicia de la Nación, visible a página 256 del Semanario Judicial de la Federación y su Gaceta, t. IX, abril de 1999, bajo el rubro: “ACCIÓN DE INCONSTITUCIONALIDAD. PARA DETERMINAR SU PROCEDENCIA EN CONTRA DE LA LEY O DECRETO, NO BASTA CON ATENDER A LA DESIGNACIÓN QUE SE LE HAYA DADO AL MOMENTO DE SU CREACIÓN, SINO A SU CONTENIDO MATERIAL QUE LO DEFINA COMO NORMA DE CARÁCTER GENERAL". De igual forma es ilustrador el criterio sostenido en la Novena Época por el Pleno de la Suprema Corte en la tesis P./J. 41/2002, visible a página 997 del Semanario Judicial de la Federación y su Gaceta, t. XVI, octubre de 2002, intitulada: "SUSPENSIÓN EN CONTROVERSIAS CONSTITUCIONALES. ES IMPROCEDENTE DECRETARLA CUANDO SE IMPUGNE UN ACUERDO EXPEDIDO POR EL JEFE DE GOBIERNO DEL DISTRITO FEDERAL, QUE REÚNA LAS CARACTERÍSTICAS DE GENERALIDAD, ABSTRACCIÓN Y OBLIGATORIEDAD PROPIAS DE UNA NORMA DE CARÁCTER GENERAL". 
pensión es emitido por el Congreso de la Unión o la Comisión Permanente de éste, por lo que de ser el primer órgano citado, el mismo podrá ser impugnado en términos de los incisos a) y b). ${ }^{73}$

Ahora bien, conforme el criterio sostenido en el presente trabajo, el decreto no es emitido por el Congreso de la Unión o su Comisión Permanente, sino por el Ejecutivo Federal, por lo que de aceptarse dicha interpretación no procedería la acción de inconstitucionalidad con fundamento en los incisos a) y b).

Sin embargo, independientemente del órgano emisor del decreto, la legitimación activa podría derivar de los incisos c) o g) de la fracción II del artículo 105 constitucional. ${ }^{74}$

El procedimiento y el decreto de suspensión de garantías previstos en el artículo 29 del pacto federal, no se encuentran exentos de control de constitucionalidad, y no debería interpretarse en forma diversa, pues si mediante éstos se despoja de eficacia a las normas por excelencia protectoras de los gobernados, que quede la certeza, derivada de su revisión, que nacieron y se mantienen respetando la norma suprema; siempre contenidos por el Estado de derecho forjado en la Constitución, donde encuentran su única justificación de existencia.

73 En caso de que el decreto haya sido emitido por la Comisión Permanente, consideramos que una posible interpretación podría permitir la impugnación del mismo por el porcentaje constitucionalmente indicado de cualesquiera cámara del Congreso; no así por un porcentaje similar de la propia Comisión Permanente, pues dicho órgano no tiene legitimación activa.

74 Puede resultar controvertido el que el procurador general de la República ejerza la acción de inconstitucionalidad si votó a favor de la medida en el procedimiento; sin embargo, de un criterio de la Suprema Corte podría derivarse opinión en contrario, tal y como se desprende de la jurisprudencia P./J. 122/2006, emitida en la Novena Época por el Pleno de la Suprema Corte de Justicia de la Nación, visible a página 879 del Semanario Judicial de la Federación y su Gaceta, t. XXIV, noviembre de 2006, cuyo rubro indica: "DERECHO DE VETO. LA OMISIÓN DE SU EJERCICIO POR PARTE DEL PRESIDENTE DE LA REPÚBLICA EN RELACIÓN CON UNA LEY FEDERAL QUE IMPUGNA EN CONTROVERSIA CONSTITUCIONAL, NO IMPLICA EL CONSENTIMIENTO TÁCITO DE ESA LEY NI LA IMPROCEDENCIA DEL JUICIO". 


\section{BIBLIOGRAFÍA}

AgUILAR y MAYA, José, Breve reseña de la legislación de emergencia expedida en los Estados Unidos Mexicanos, con motivo de su participación en el actual conflicto mundial, incluyendo las leyes y reglamentos formulados por la Procuraduría General de la República y las disposiciones legislativas que con éstos tienen más estrecha relación, México, Procuraduría General de la República, 1944.

ARTEaga NAVA, Elisur, Derecho constitucional, 2a. ed., México, Oxford, 1999.

BAZDRESCH, Luis, Garantías constitucionales, 5a. ed., México, Trillas, 1998.

BuRGOA, Ignacio, Derecho constitucional mexicano, 9a. ed., México, Porrúa, 1994.

___ La legislación de emergencia y el juicio de amparo, México, Hispano-Mexicana, 1945.

-, Las garantías individuales, 25a. ed., México, Porrúa, 1993.

CARPIZO, Jorge, Estudios constitucionales, 2a. ed., México, Instituto de Investigaciones Jurídicas-UNAM, 1983.

—_ L L Constitución mexicana de 1917, 11a. Ed., México, PorrúaUNAM, Instituto de Investigaciones Jurídicas, 1998.

CASTRO, Juventino, Garantías y amparo, 8a. ed., México, Porrúa, 1994.

SILVA, Gustavo de, "El cumplimiento de disposiciones constitucionales en el procedimiento legislativo", en CALVO, Enrique (coord.), Propuesta de reformas legales e interpretación de las normas existentes, México, Barra Mexicana, Colegio de Abogados, Themis, 2002, t. I.

Vega García, Pedro de, Estudios político constitucionales, México, UNAM, Instituto de Investigaciones Jurídicas, 1987.

DÍAZ, Elías, Estado de derecho y sociedad democrática, 9a. ed., Madrid, Taurus, 1981.

FERRER MuÑOZ, Manuel, La Constitución de Cádiz y su aplicación en la Nueva España, México, UNAM, Instituto de Investigaciones Jurídicas, 1993.

FIX FIERRO, Héctor, Artículo 29. Derechos del pueblo mexicano, LV Legislatura de la Cámara de Diputados del Congreso de la Unión, 4a. ed., México, Porrúa, 1994, t. V. 
FIX-ZAMUDIO, Héctor y CARMONA TINOCO, Jorge Ulises, “Algunos comentarios al título primero, capítulo primero de la Constitución federal. Derechos fundamentales", en CARBONELL, Miguel y VALADÉS, Diego (coords.), Panorama del derecho constitucional mexicano, México, Porrúa-UNAM, 2006.

HERRENDORF, Daniel, El poder de policía en un sistema de derechos humanos, México, Instituto Nacional de Ciencias Penales, 1990.

Madrazo, Jorge, Constitución Política de los Estados Unidos Mexicanos comentada. Artículo 29 constitucional, 4a. ed., México, UNAM, Instituto de Investigaciones Jurídicas y otras, 1993.

PÉREZ LuÑO, Antonio E., Los derechos fundamentales, 5a. ed., Madrid, Tecnos, 1993.

PRIETO SANCHÍs, Luis, Constitucionalismo y positivismo, México, Fontamara, 1997.

Rubio Llorente, Francisco, La forma del poder, Madrid, Centro de Estudios Constitucionales, 1997.

SÁNCHEZ BRINGAS, Enrique, Derecho constitucional, 4a. ed., México, Porrúa, 1999.

SCHMILL, Ulises, El sistema de la Constitución mexicana, México, Porrúa, 1971.

y SILVA, Gustavo de, "La sanción ante el incumplimiento de la sentencia de amparo", El Foro. La ejecución de sentencias de amparo, la repetición del acto reclamado y la negativa a suspenderlo, México, décimo cuarta época, t. XVIII, núm. 2, Barra Mexicana Colegio de Abogados, 2005.

SCHMITT, Carl, Defensa de la Constitución, 2a. ed., trad. de Manuel Sánchez Sarto, Madrid, Tecnos, 1998.

TENA RAMíreZ, Felipe, Derecho constitucional mexicano, 29a. ed., México, Porrúa, 1995.

VALADÉS, Diego, Constitución y política, 2a. ed., México, UNAM, Instituto de Investigaciones Jurídicas, 1994. 